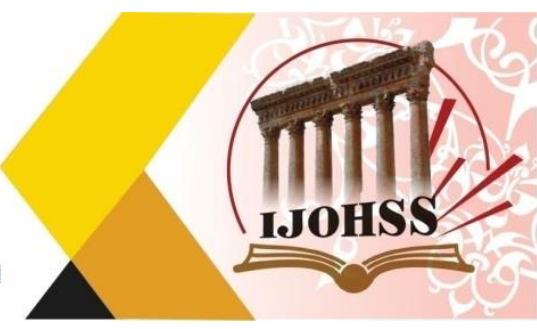

\title{
الأصول الغامضة للقائد سرجون الأكدي وأثرها في صياغة شخصية البطل
}

\author{
د. محمد صبري عبد الرحيم \\ الهيأة العامة للآثار والتراث الرئ

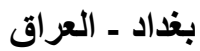

\author{
أ.د. رغد عبد القادر عباس \\ قسم التاريخ \\ كلية التربية ـ الجامعة المستنصرية

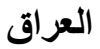

البريد الاكتروني: raghadabdulqadir@gmail.com

بالر غم من قلة المعطيات التاريخية التي تنتاول سيرة هذا القائد العظيم و أصوله التي إنحدر منها، التي كتب هو التها

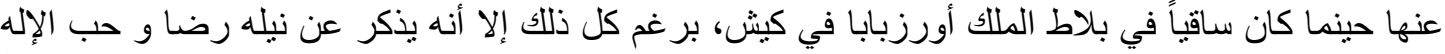

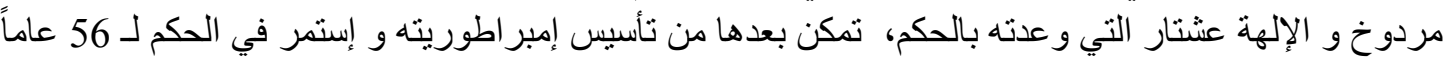
حقق خلالها ما عجز عنه الكثير من حكام العالم القديم و خلف في الحكم سلسلة من القادة العظام و و على رأسهر نر ام - سين حفيده. "فإن كانت الرواية التي إكتنفها غموض و المتعلقة بو لادة هذا القائد التاريخي و رحلته و مسيرة حياته التي طغى التى الته عليها كم من هالات التقديس و الغموض، إن كانت هذه الطروحات صحيحة، فلا يمكن عندها القول النها أنه كان قائداً

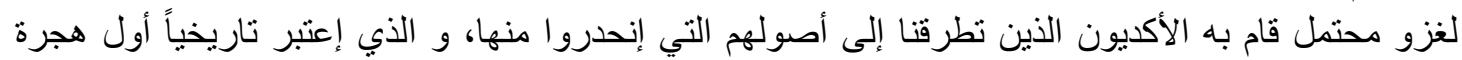

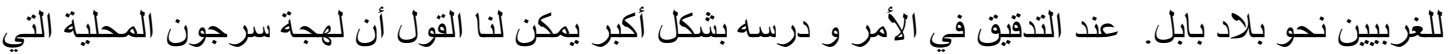

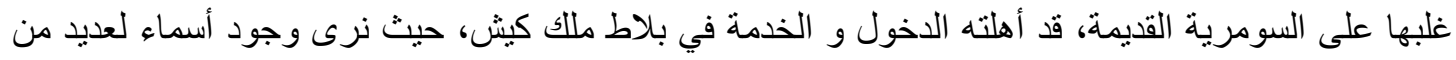

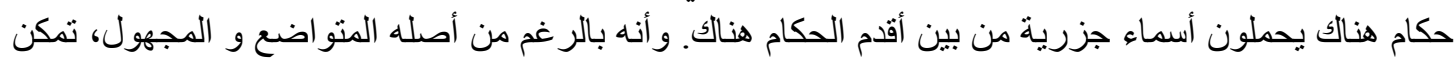

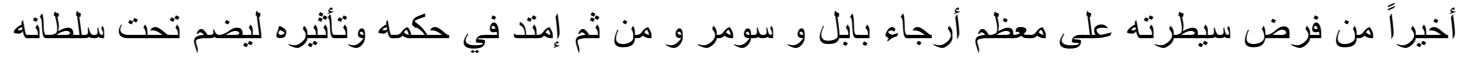

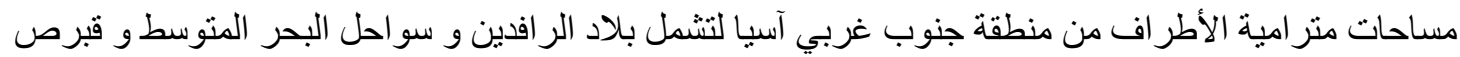

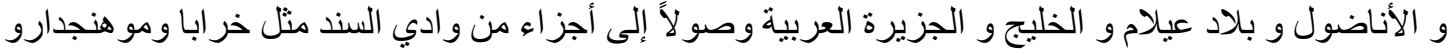
و كذللك بدخشان في أفغانستان".

الكلمات المفتاحية: سرجون الأكدي، العر اق القديم، شخصية البطل. 


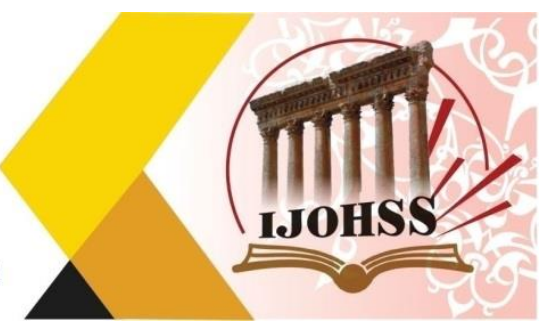

\title{
The Mysterious Origins of the Leader Sargon of Akkad and its Impact on the Formulation of the Character of the Hero
}

\author{
Prof. Dr. Raghad Abdel Qader Abbas \\ History Department \\ College of Education - Al-Mustansiriya \\ University \\ Iraq \\ Email: raghadabdulqadir@gmail.com
}

\author{
Dr. Mohamed Sabry Abdel Rahim \\ The State Board of Antiquities and \\ Heritage \\ Baghdad, Iraq
}

\begin{abstract}
Despite the lack of historical data dealing with the biography of this great leader and his origins from which he descended, which he wrote about when he was a (Drink Offered) in the court of King Urzbaba of Kish.

When examining and studying further, we can say that the local Sargon dialect, which prevailed over the ancient Sumerian, was qualified to enter and serve in the court of the King of Kish, where we see the names of many with Semitic names among the oldest rulers there. despite all this, he mentions the satisfaction and love of the god Murdoch and the goddess Ishtar, who promised him to rule. He finally managed to establish his empire and continued to rule for 56 years during which he achieved what many rulers of the old world and succeeded in the verdict a series of great leaders, led by His Grandson Nram-Suen. "If the story that has been shrouded in mystery concerning the birth of this historic leader, his journey and the march of his life, which has been overshadowed by how many halos of sanctification and ambiguity, if these proposals are true, then it cannot be said that he was the leader of a possible invasion by the AKadians, whom we previously discussed their origins, which was historically considered the first exodus of Westerners to Babylon. Despite his humble and unknown origin, he finally gained control over most of Babylon and Sumer and then extended his rule and influence to include sprawling areas of South-West Asia to include Mesopotamia, the Mediterranean coasts, Cyprus, Anatolia, Elam, the Gulf and Arabia, as well as parts of the Sindh Valley such as Kharba and Mohangdaro, as well as Badakhshan in Afghanistan.
\end{abstract}

Keywords: Sargon of Akkad, ancient Iraq, hero character. 


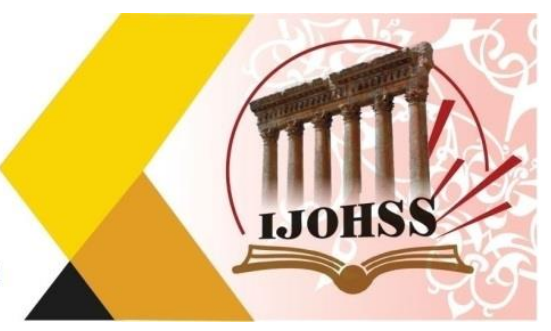

مقامة

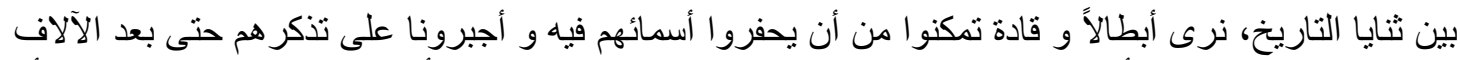

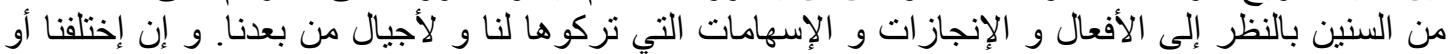

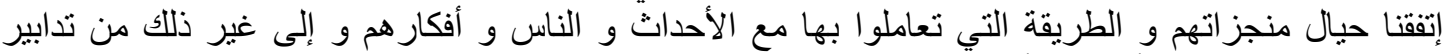
إنخذوها، فإننا لا يمكن أن نغفل أو نتجاهل بر اعتهم و حنكتهم الإدارية و الإنجاز ات التهات التي حققو ها في كافة ميادين

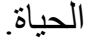

و على الرغم من طروحات السبق الحضاري و السعي إلى إبراز مكانة الأبطال و القادة التاريخيين ممن تتفاخر

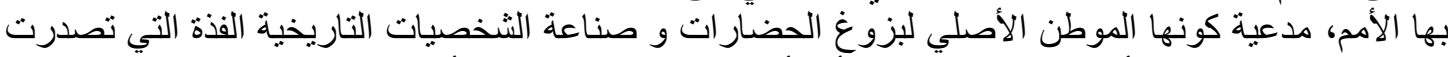

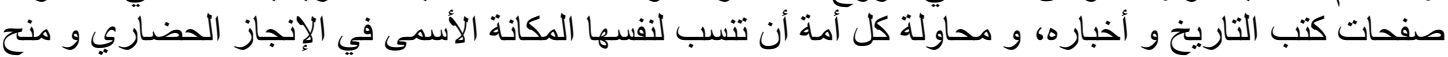

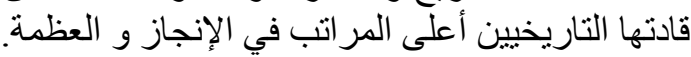

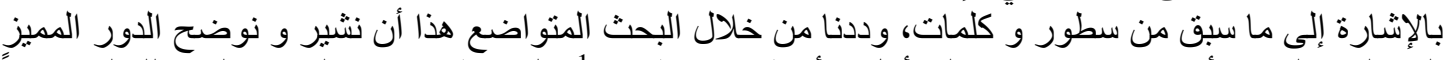

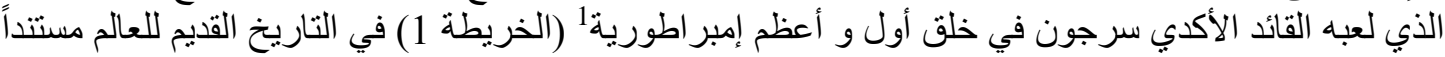

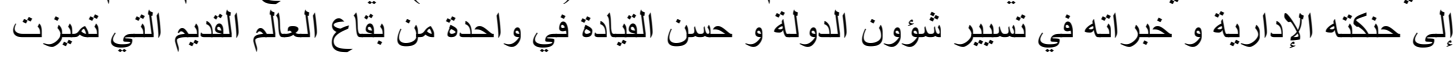

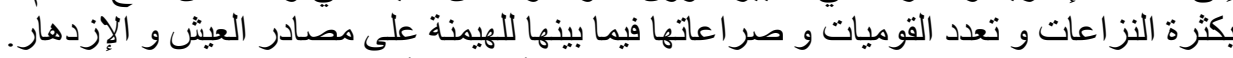

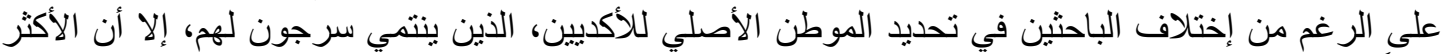

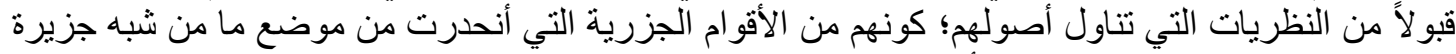

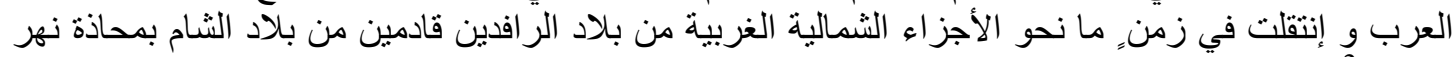
الفر ات.

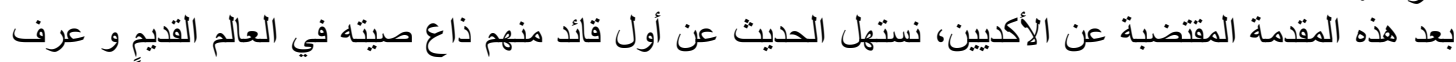

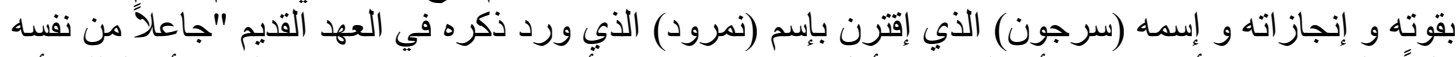

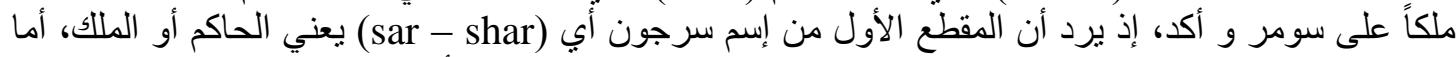

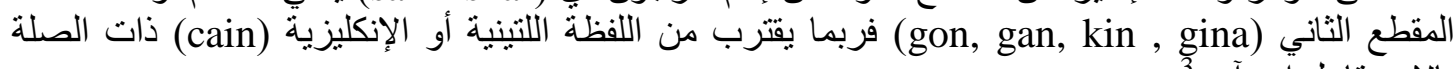
بالإسم قابيل إبين آدم.

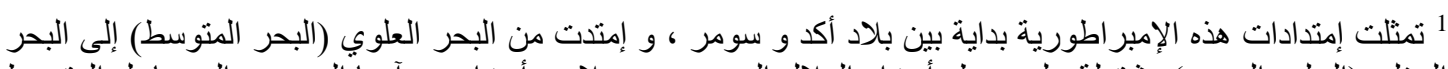

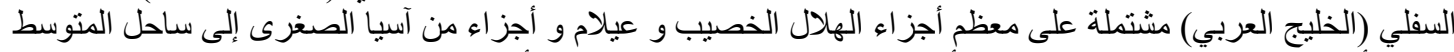
و ربمًا أبعد من ذلك حيث عدت واحدة من أعظم إمبر اظظوريات الثرق القئ القيم و أولها. Brian Lewis, “The Sargon Legend", ASOR, Cambridge, 1980, P. 110.

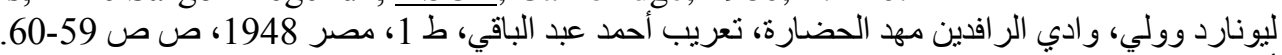

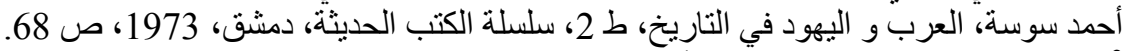

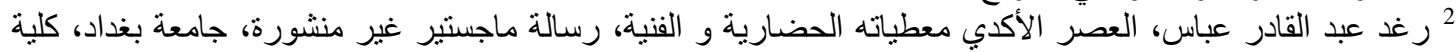

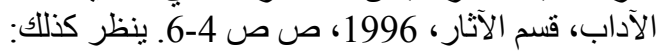

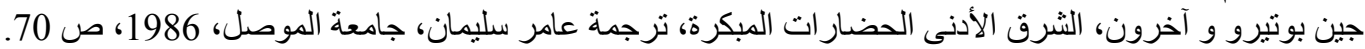

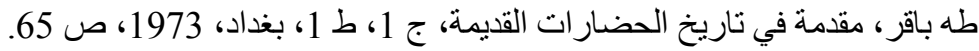

${ }^{3}$ Mary, G. Hauslon., Ancient Egyptian Mesopotamian Persian Costume and Decoration, London, 1854, PP 115-116. 


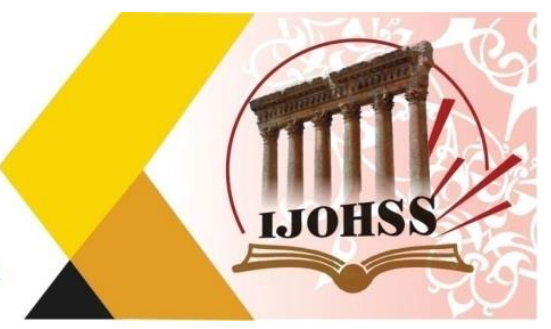

ذكرت النصوص المسمارية هذا الملك بالإسم (شاروكين sharru -kin) التي تعني الملك الصادق أو الملك

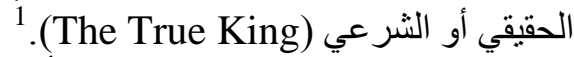

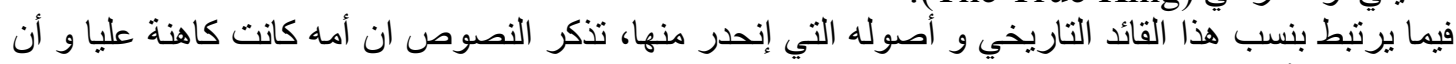

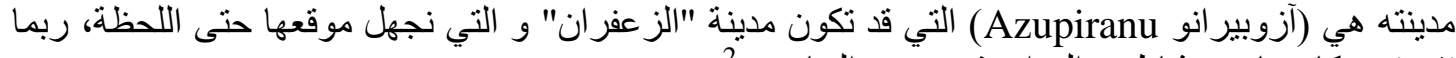

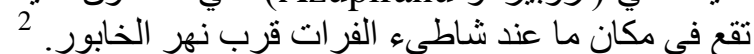

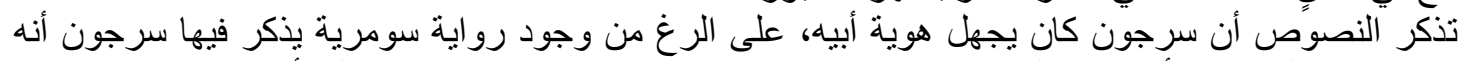

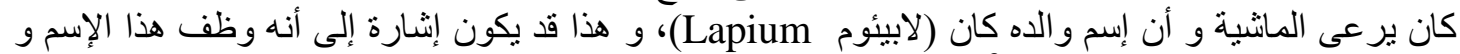
إستخدمه ربما ليكسب عطف النية الناس.

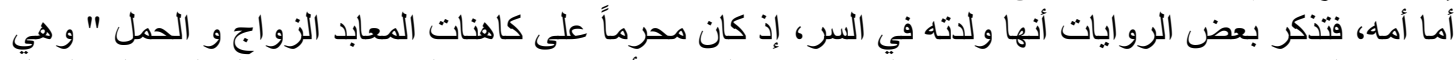

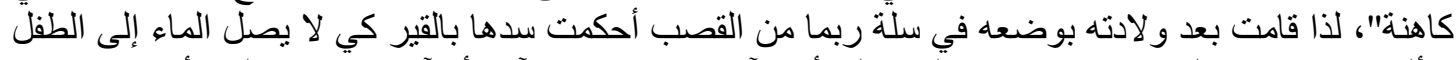

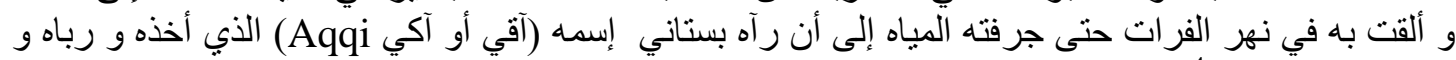
علمه حرفة التبتنتة. "إن قصة أصل سرجة البقون و نسبه تشبه إلى حدٍ كبير قصة النبي موسى عليه السلام، إذ بظهر الثبه فئه في الطريقة

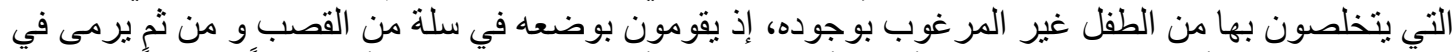

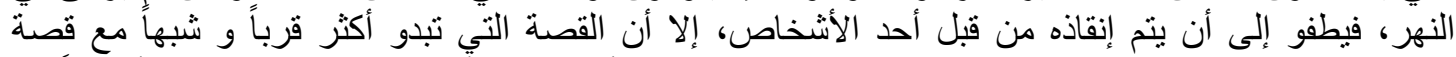

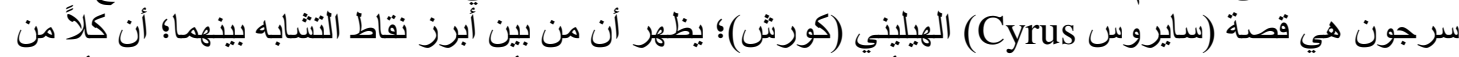

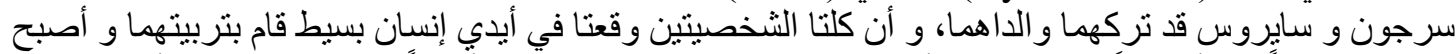

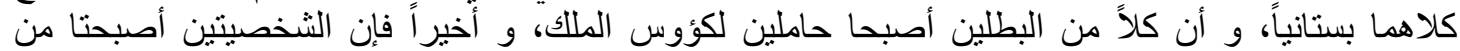

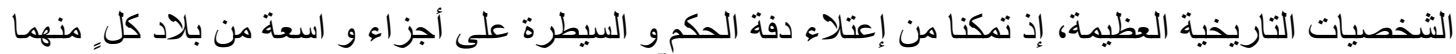

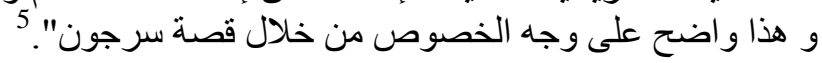

${ }^{1}$ Dury, Carel J. ., Volker der Alten Orient, Baden, 1969, PP. 69-73.

Schulze Franz., Art, Architecture and Civilization, University of Virginia, 1968, P. 65.

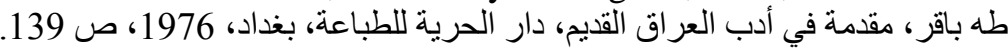

${ }^{2}$ William W. Hallo and William K. Simpson., The Ancient Near East; A History, U.S.A., 1971, P. 55.

رغد عبد القادر عباس، مصدر سابق، 1996، ص الإب 11-12.

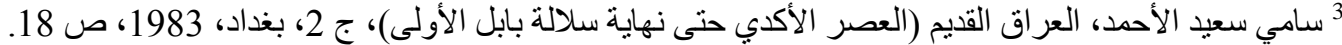

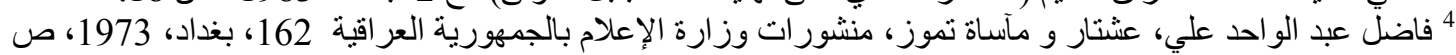

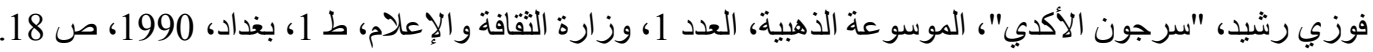

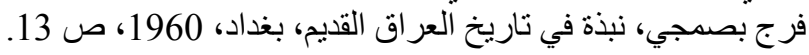
Seton Lloyd E.S.A., Twin Rivers, Oxford, 1943, PP. 31-33.

Nicholas Postgate, The First empires, Belgium, 1977, PP. 77-78.

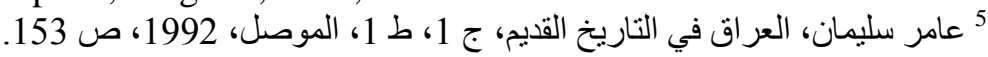
Brian Lewis, "The Sargon Legend- A Study of the Akkadian Text and the Tale of the Hero at Birth", JNES, Vol. 43, 1984, P. 76.

Drews Robert, "Sargon Cyrus and Mesopotamian Folk History", JNES, Vol. 33, No. 4, Chicago, 1947, PP. 388-390.

Sidney Smith, Early History of Assyria to 1000 B.C., London, 1928, P. 82. 


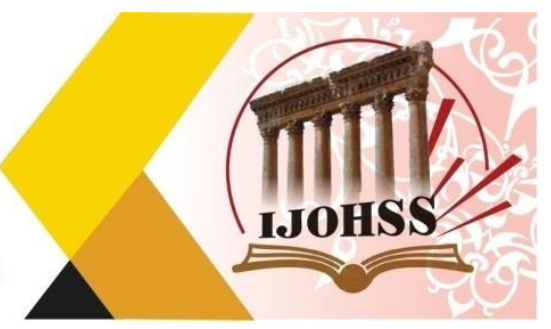

فيما يتعلق بالتاريخ السياسي لسرجون الأكدي فلم يكن ليبدأ إلا بعد أن غادر كيش الباد و تذكر الأسطورة الخاصة

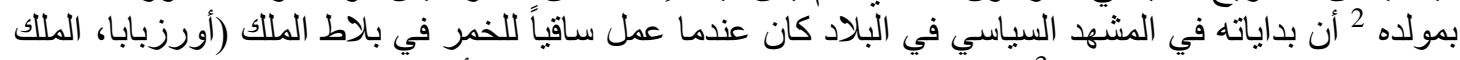

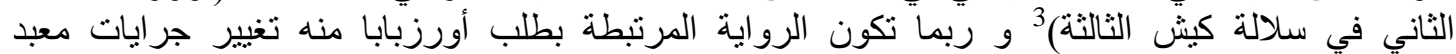

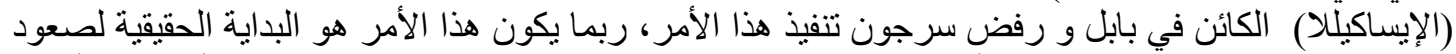

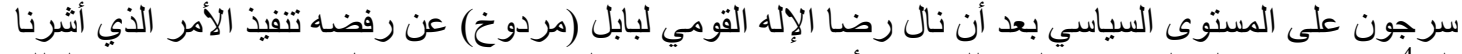

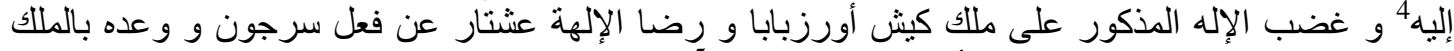

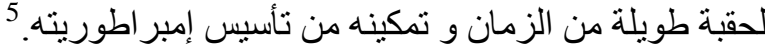

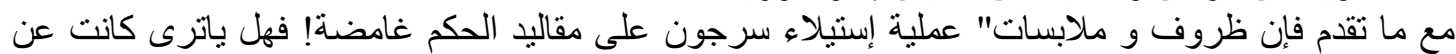

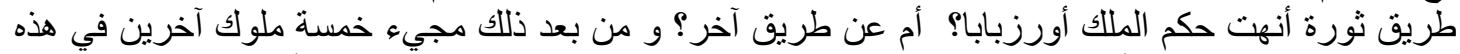

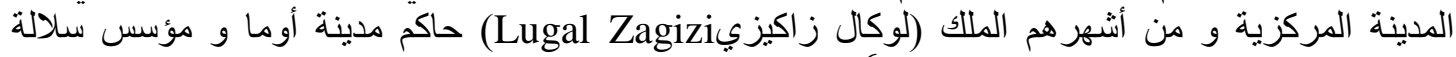

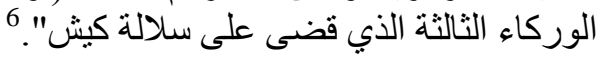

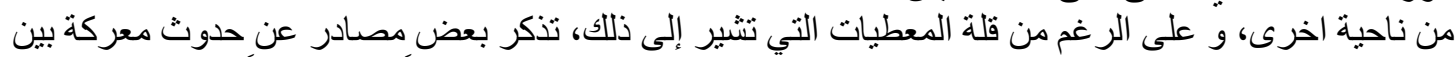

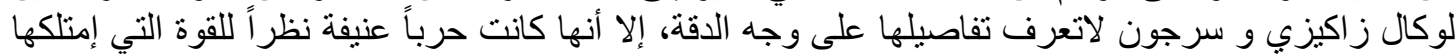

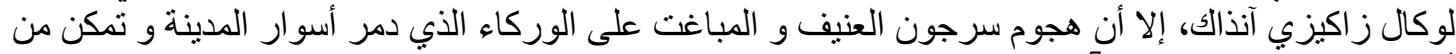

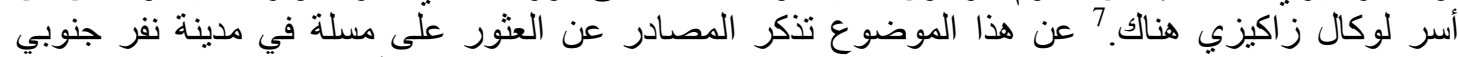

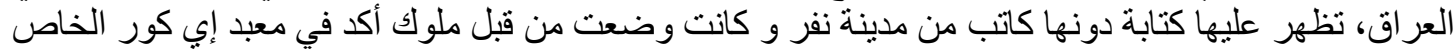

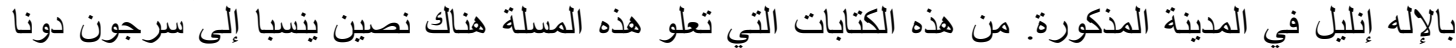

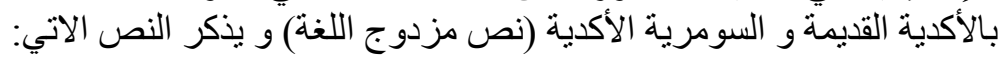

${ }^{1}$ J.E.S. Edawrds, C. J. Cadd, N. E. L. Hammond, The Cambridge Ancient History, $3^{\text {rd }}$ Edition, Cambridge University Press, 1970, P. 219.

2 هذه الأسطورة المتعلقة بمولد سرجون الأكدي منوفرة بنسختين غبر مكتملة بالخط الآشوري الحديث فضلاً عن كسرة

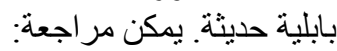

J. B. Pritchard, “Akkadian Myths and Epics”, Edited by Speiser, ANET, New Jersey, 1969, P. 119.

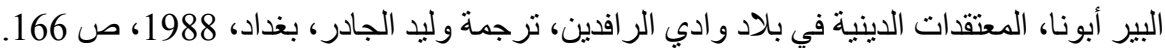

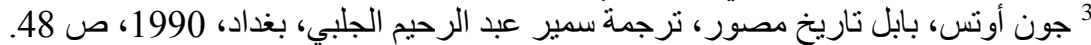

$$
\begin{aligned}
& \text { عامر سليمان و أحمد مالك الفتيان، محاضر ترات في في التاريخ القديم، بغداد، 1978، 1978، ص } 97 .
\end{aligned}
$$

Nicholas Postgate, Op. Cit., 1977, PP. 77-78.

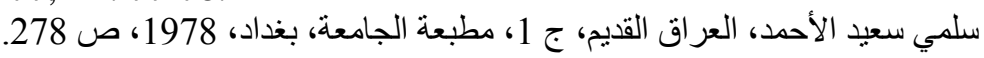

Henry Frankfort, Birth of Civilization in the Near East, New York, 1950, PP. 82-83.

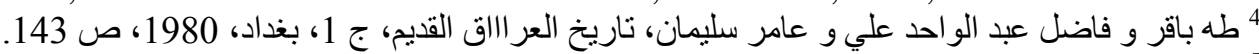

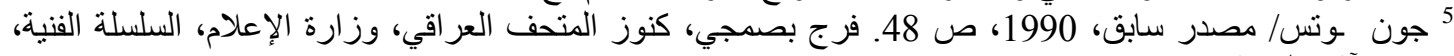

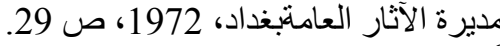

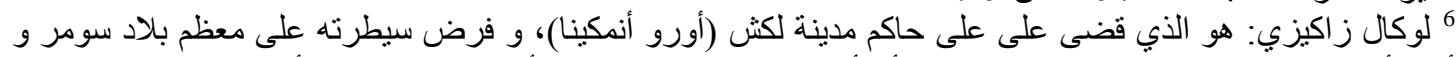

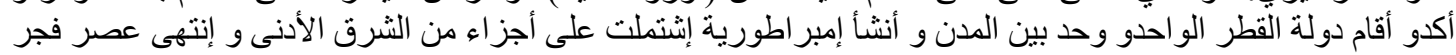
السلالات السومرية بنهاية حكمه.

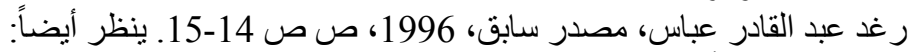

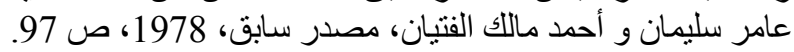

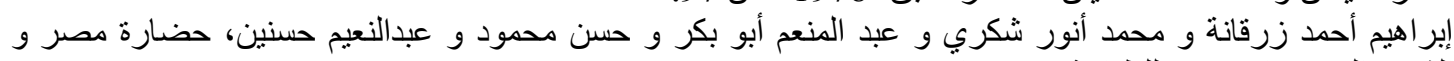

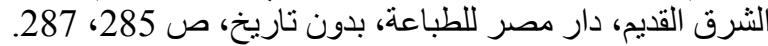

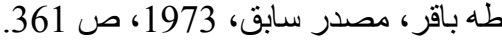
7 رغد عبد القادر عباس، مصدر سابق، 1996، ص صد 15. 


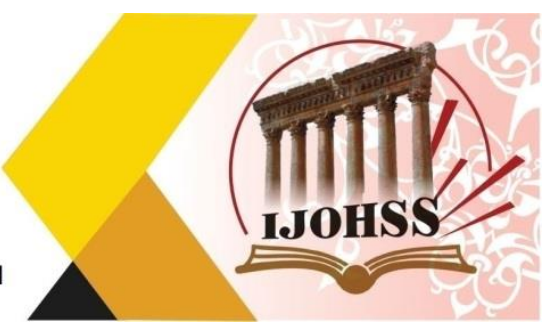

"أن سرجون أسر لوكال زاكيزي ملك الوركاء في معركة جرت بينهما و قد إنتصر فيها سرجون الأكدي و قام

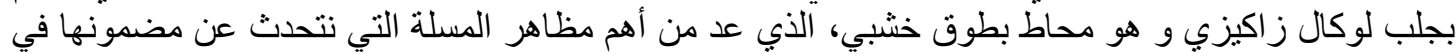

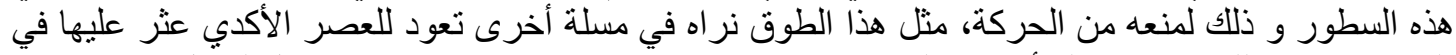

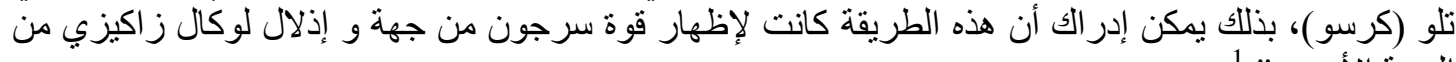

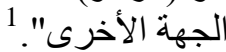

من عو امل الغموض الأخرى التي يمكن الحديث عنها أيضاً، موضع العاصمة الأكدية (أكد) و أصل التسمية؛ أما

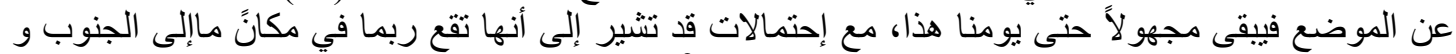

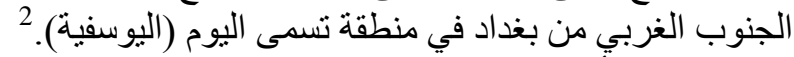

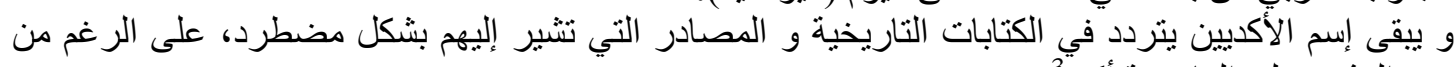
عدم العثور على العاصمة أكد." العبئ

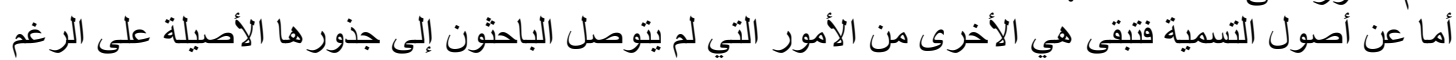

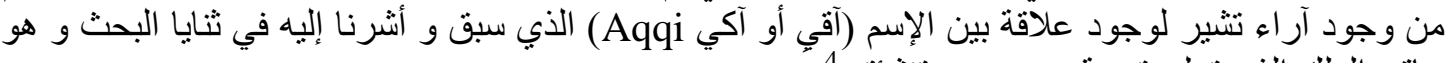

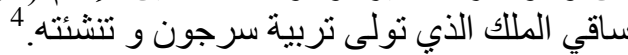

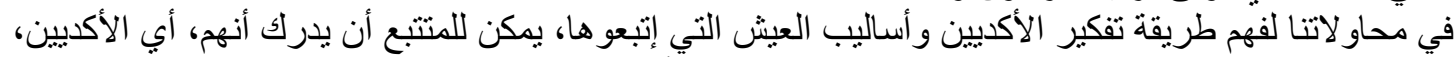

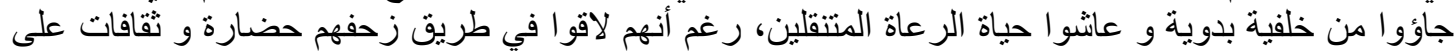

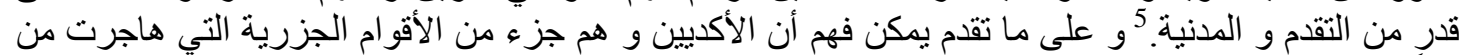

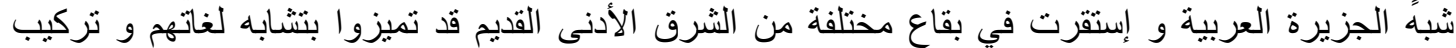

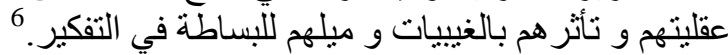

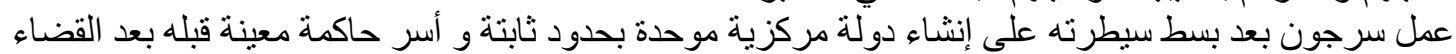

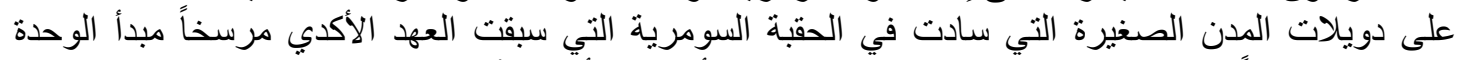

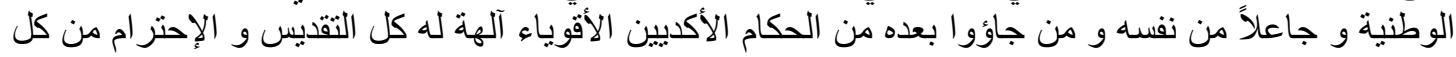

${ }^{1}$ Edmund I. Gordon, "Of Princes and Foxes: The Neck-Stock in the Newly Discovered Agade Period Stele”, Sumer, Vol. XII, No. 1-2, Baghdad, 1956, PP. 80, 83-84.

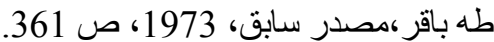

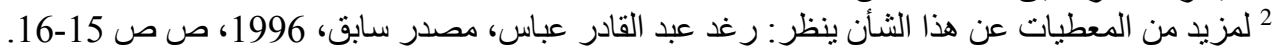

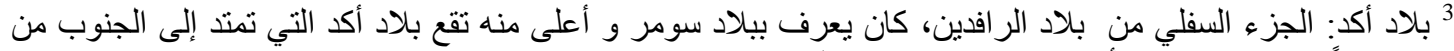
بغدادو كلاً من بلاد سومر و أكد كانت تعرف بيلاد بابل.

Henry S. Lucas, A Short History of Civilization, York, 1943, P. 14.

Jack Finegan, Light From the Ancient Past, U.S.A., 1954, P. 38.

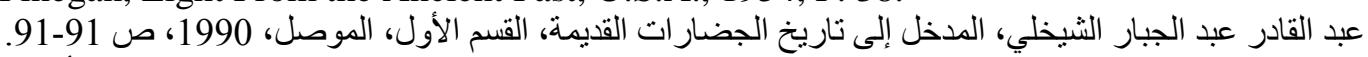

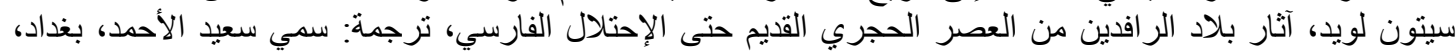

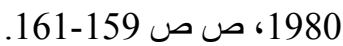
نيكو لاي بوستغيت، حضارة العراق و آثاره ـ تاريخ مصور، نرجمة: سمير عبد الرحيم الجلبي، دار المأمون للترجمة و

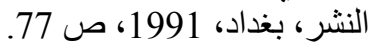
" عبد الكريم عبدالله، "ألقاب حكام السلالات و إسم أكد"، مجلة كلية الآداب، ملحق، بغداد، 1978، ص صد 245-246.

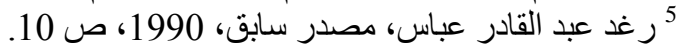
Adil Naji, Akkadian Cylinder Seals in the Iraq Museum, Unpublished M. A. Thesis, Birmingham University, 1965, P. XII.

Henry S. Lucas, OP. Cit., 1943, P. 72.

$$
6 \text { صالح أحمد العلي، محاضر ات في تاريخ العرب، ط2، ج 1، بغداد، 1959، ص } 6 .
$$




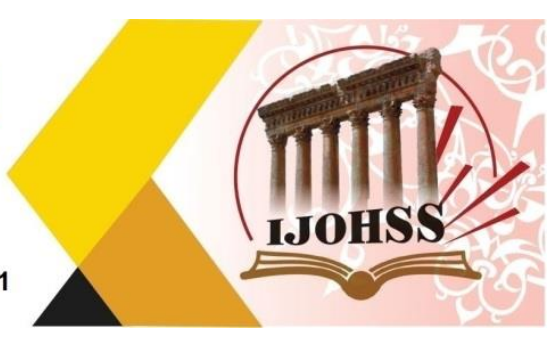

الأقو ام التي تعيش في كنف النظام السياسي الإمبراطوري الجديد الذي نِشأ لأول مرة في الثرق القديم على هذا المستوى من الإتساع و الثمولية.

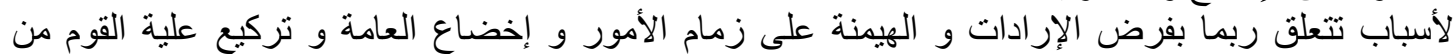

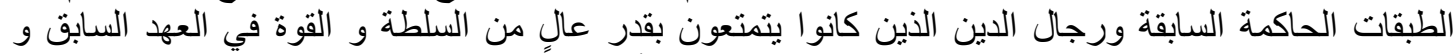

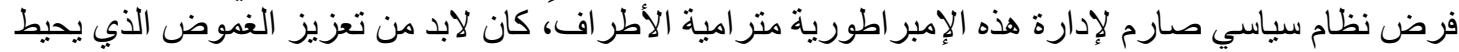

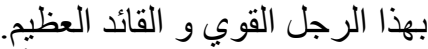

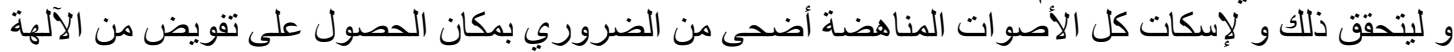

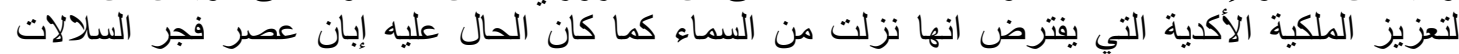

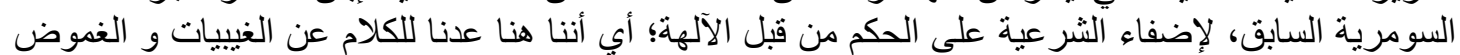

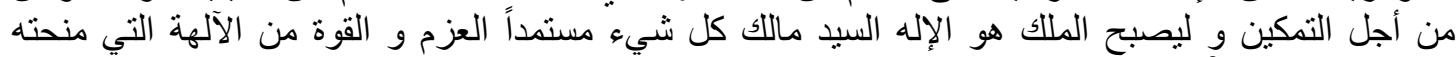
الثر عية والسلطة.

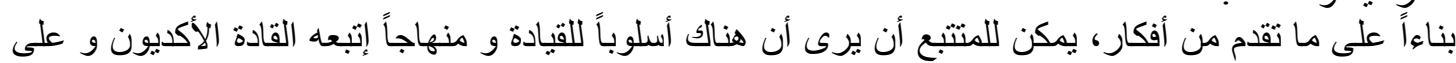

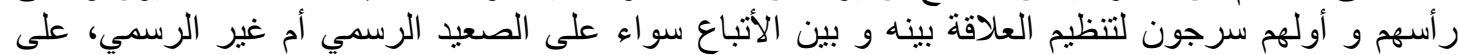

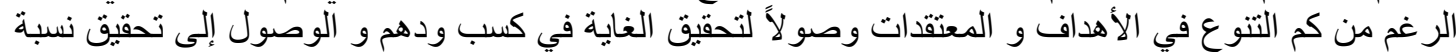

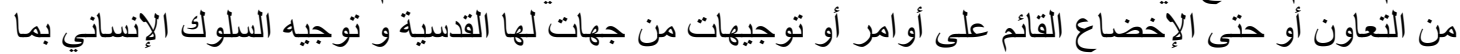

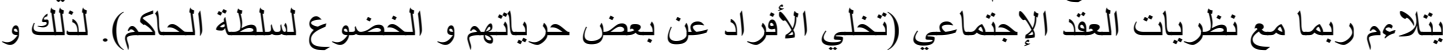

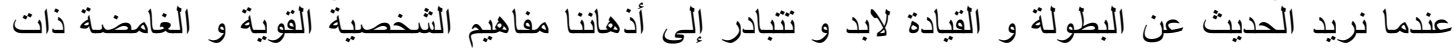

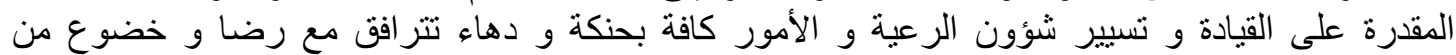

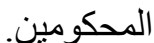

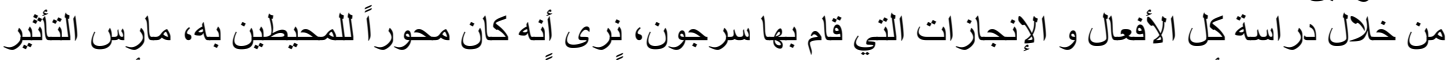

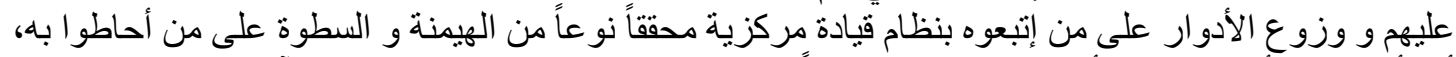

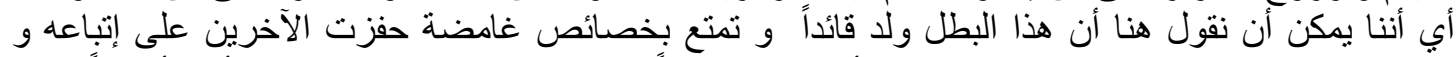

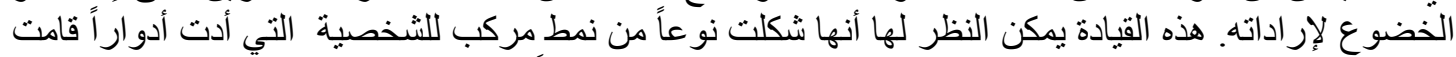

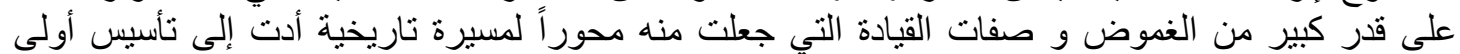

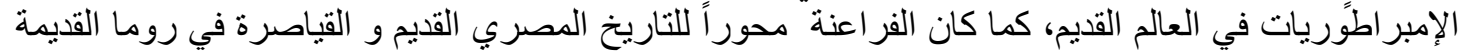

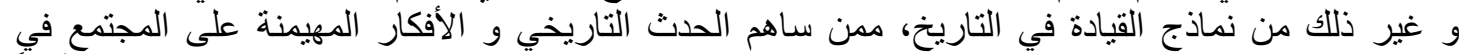

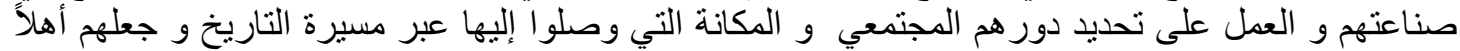

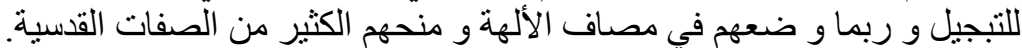

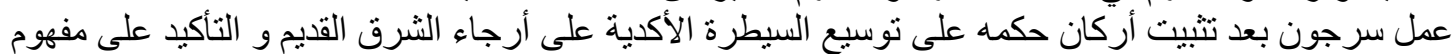

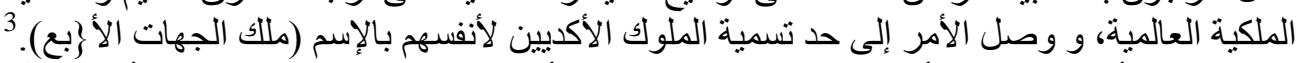

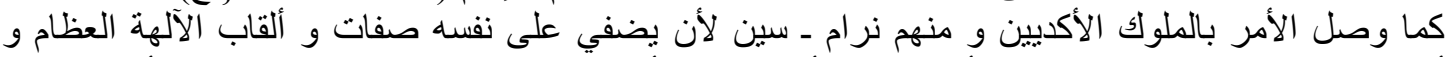

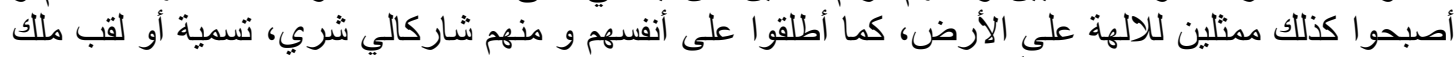
العالم و ملك أو سيد سومر و أكد. 1

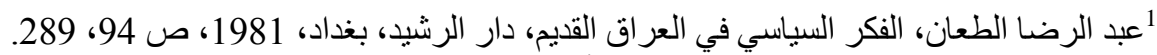

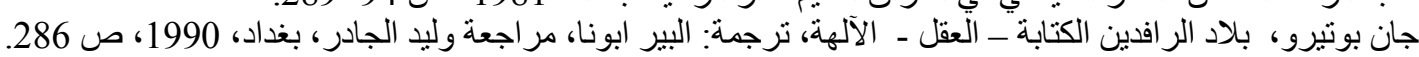
Robert McC Adams, Land Behind Baghdad, Chicago, 1965, P. 43.

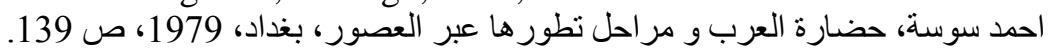

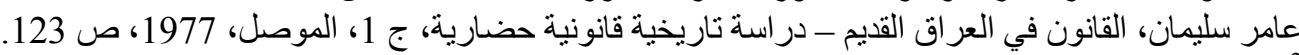

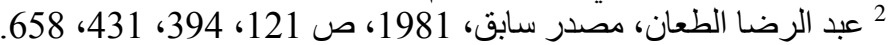

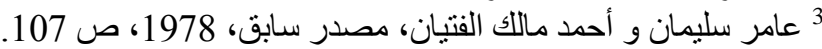
جان بوتيرو، مصدر سابق، 1986، ص صل 113. 


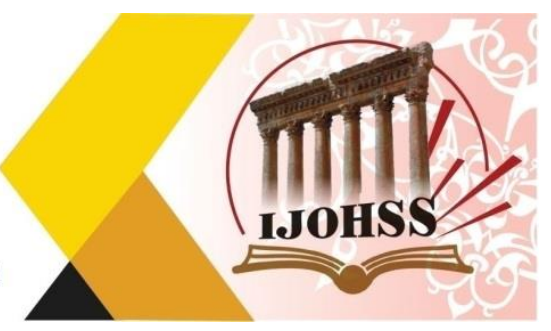

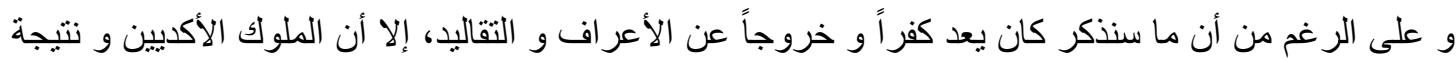

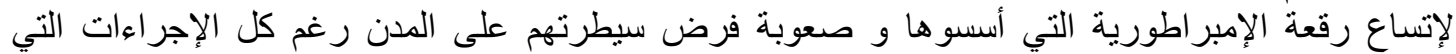

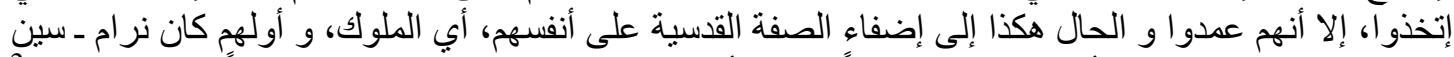

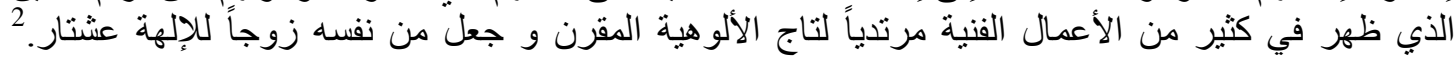

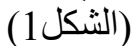

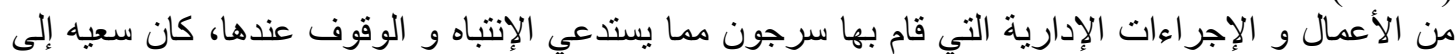

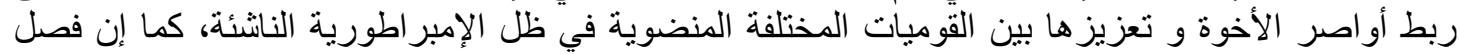

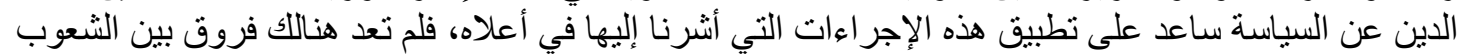

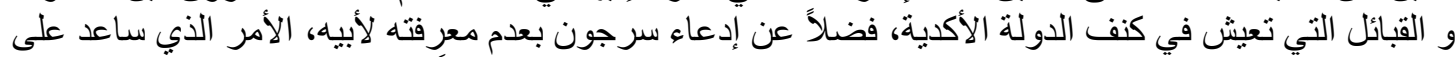

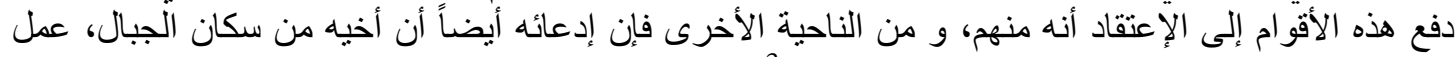

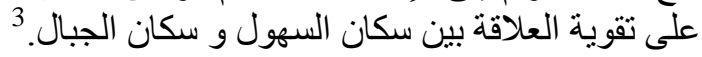

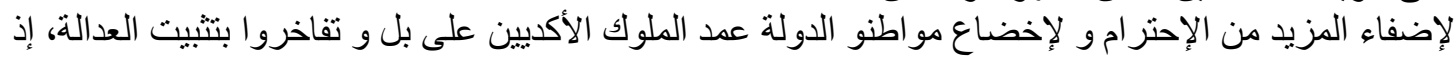

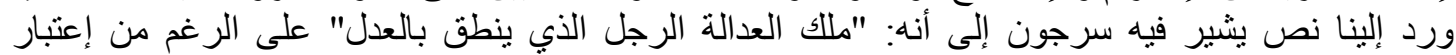

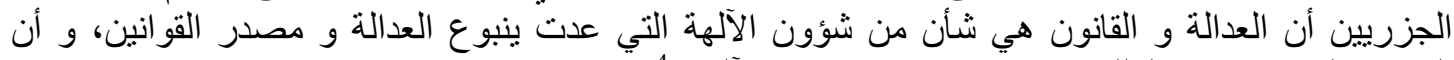

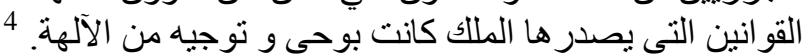

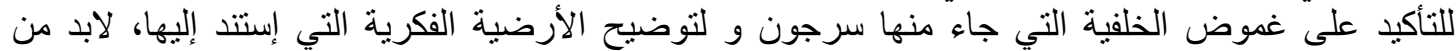

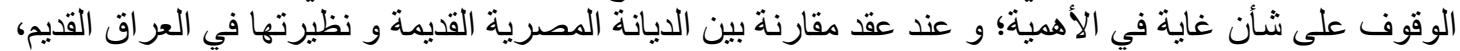

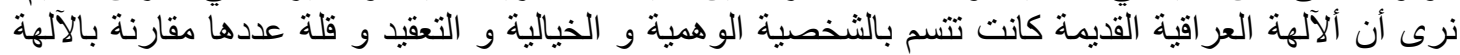

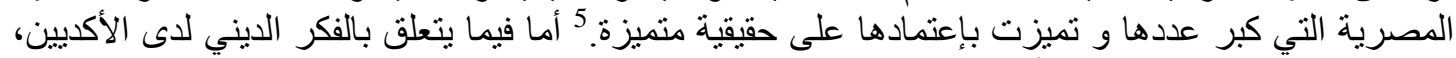

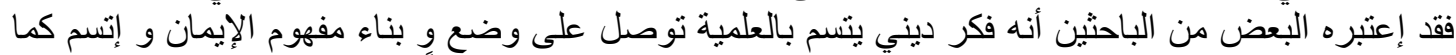

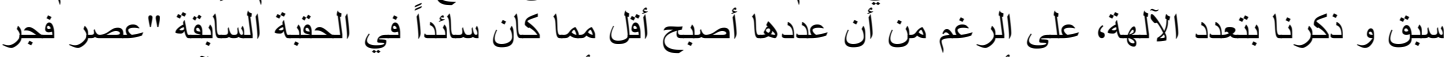

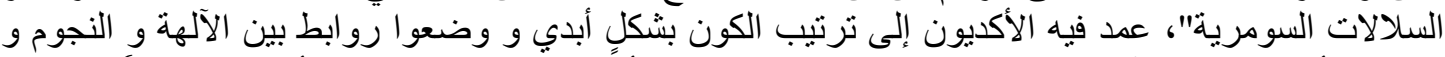

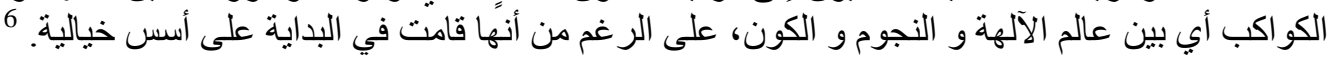

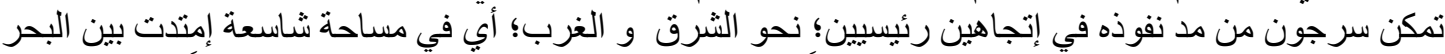

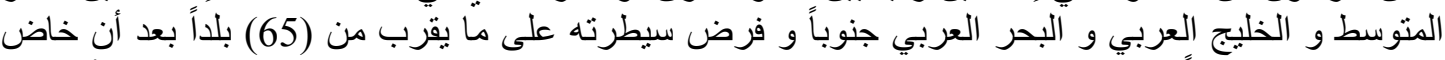

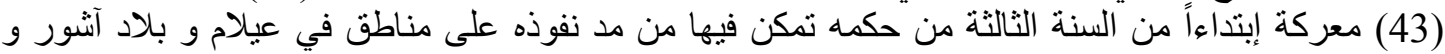

Erica Hunter, First civilization, Belgium, 1994, P. 53.

1 سامي سعيد الأحمد، مصدر سابق، 1983، ص 4071

C.J. Cadd, The Cambridge Ancient History, Vol. !, Part 2, Cambridge, 1971, P. 441.

سامي سعيد الأحمد، "الإدارة و نظام الحكم"، حضارة العراق، ج2، تأليف نخبة من الباحثين، بغداد، 1985، ص 177

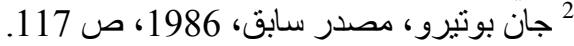

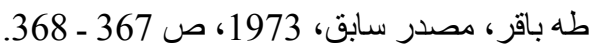

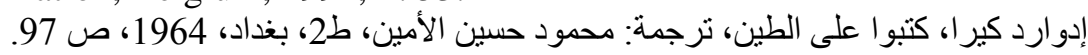

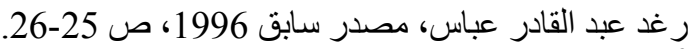

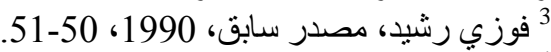

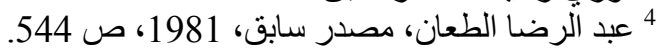

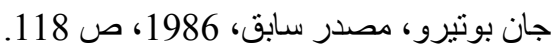

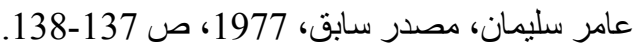

${ }^{5}$ George Rawlinson, The Religions of the Ancient World, N.Y., 1885, P. 11, 13.

6 جان بوتيرو، مصدر سابق، 1970، ص ص 7، 173-174. 


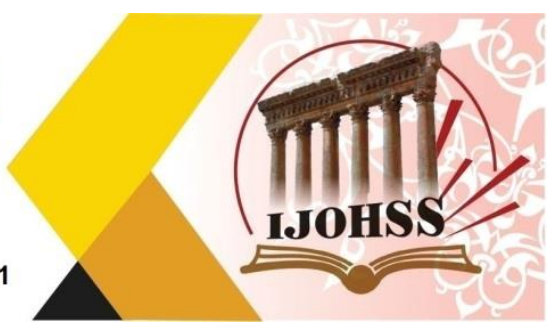

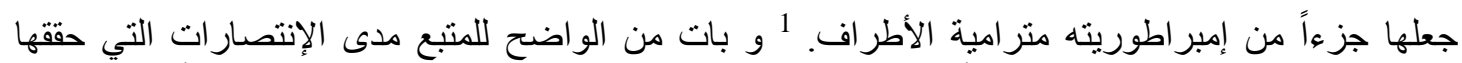

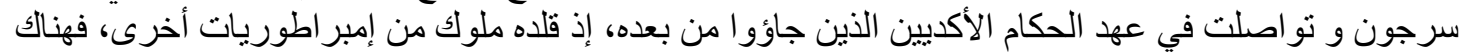

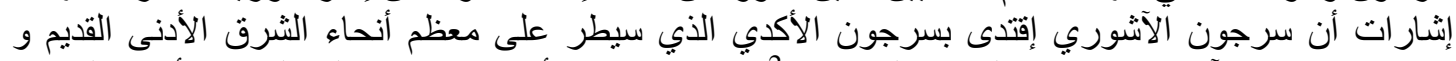

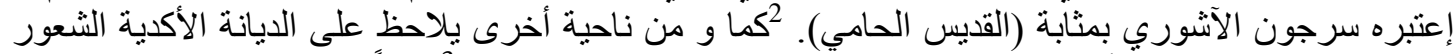

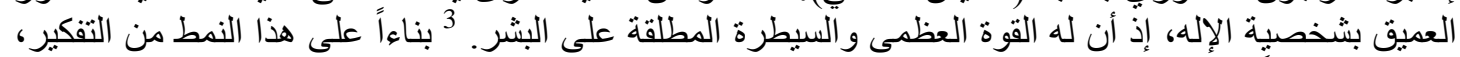

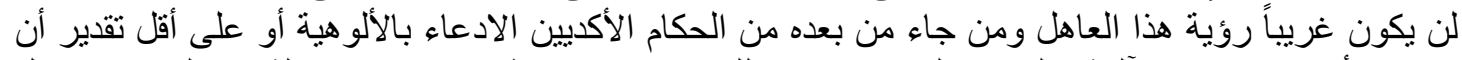

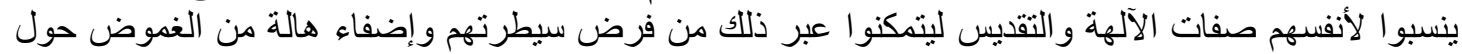

شخصياتهم.

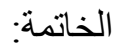

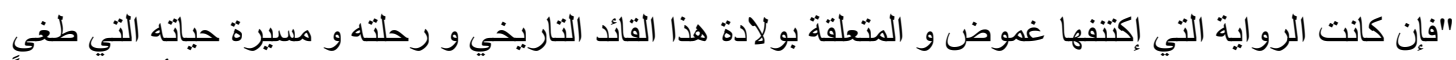

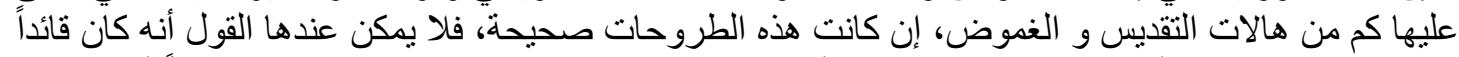

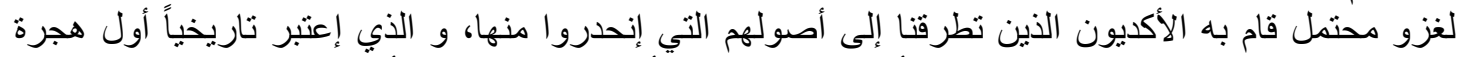

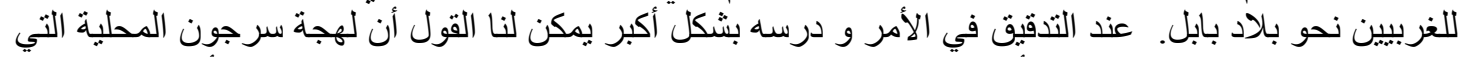

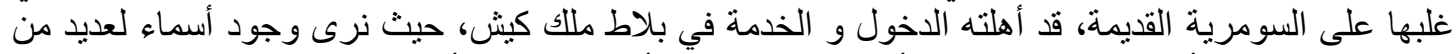

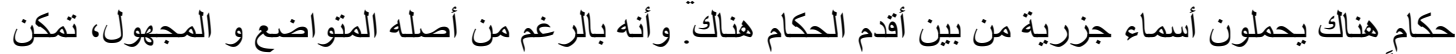

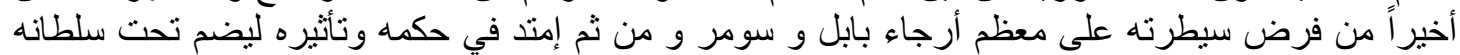

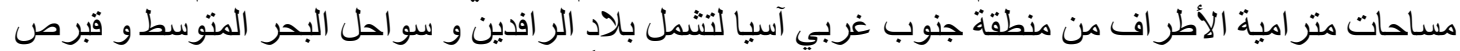

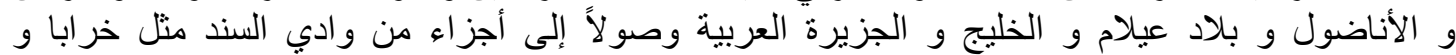
مو هنجدارو و كذلك بدخشان في أفغانستان".

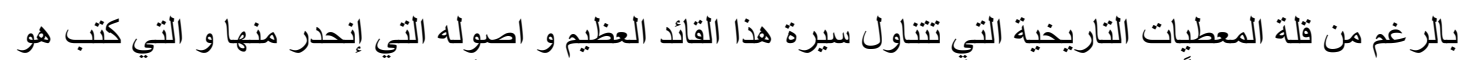

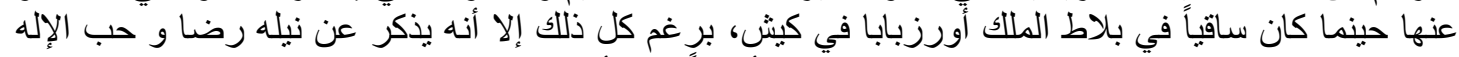

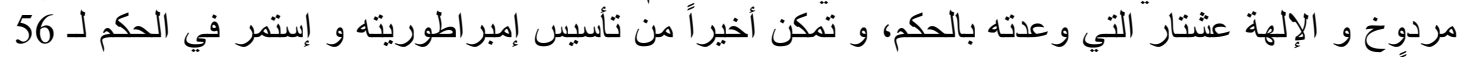

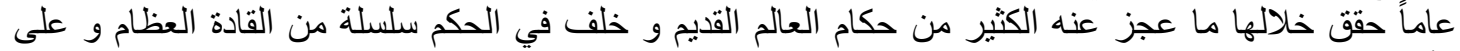
رأسهر نر ام - سين حفيداه.

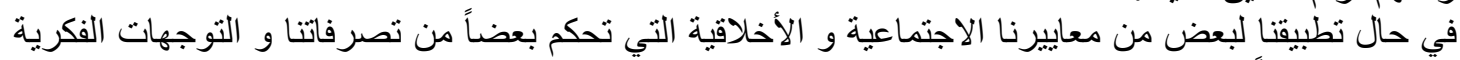

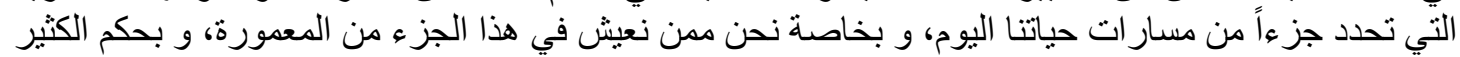

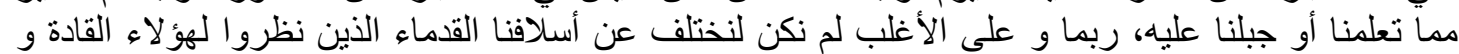

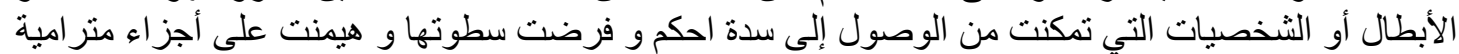

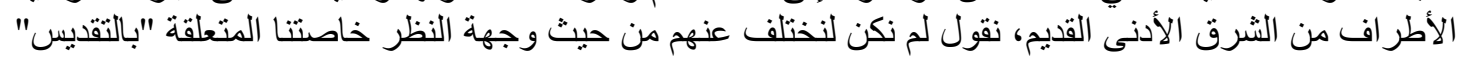

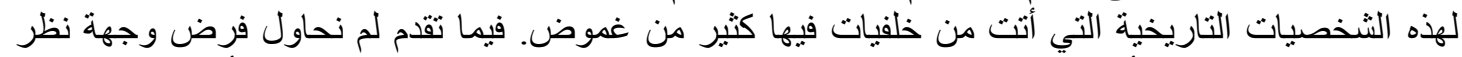

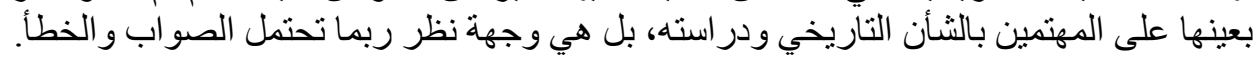

${ }^{2}$ McC Adams, Op. Cit., 1965, P. 43.bstract

1 رغد عبد القادر عباس، مصدر سابق، 1996، ص ص 57-61.

${ }^{3}$ S. C. F. Brandon, Religion in Ancient History, N. Y., 1969, P. 3. 
المجلة الحولية اللملوم الإنسانية والإمتاعية International Journal on Humanities and Social Sciences website:www.ijohss.com Email:editor@ijohss.com العدد (27) نوفمبر 2021 ISSN: $2415-4822$

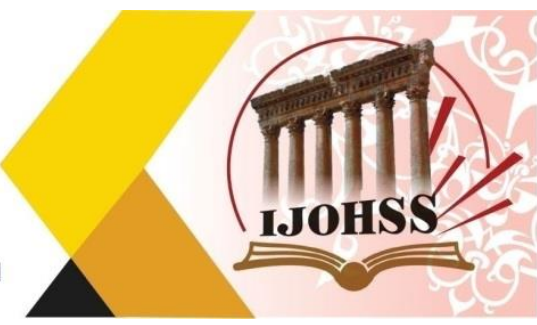

خريطة (1) تظهر إمتدادات الإمبر اطورية الأكدية

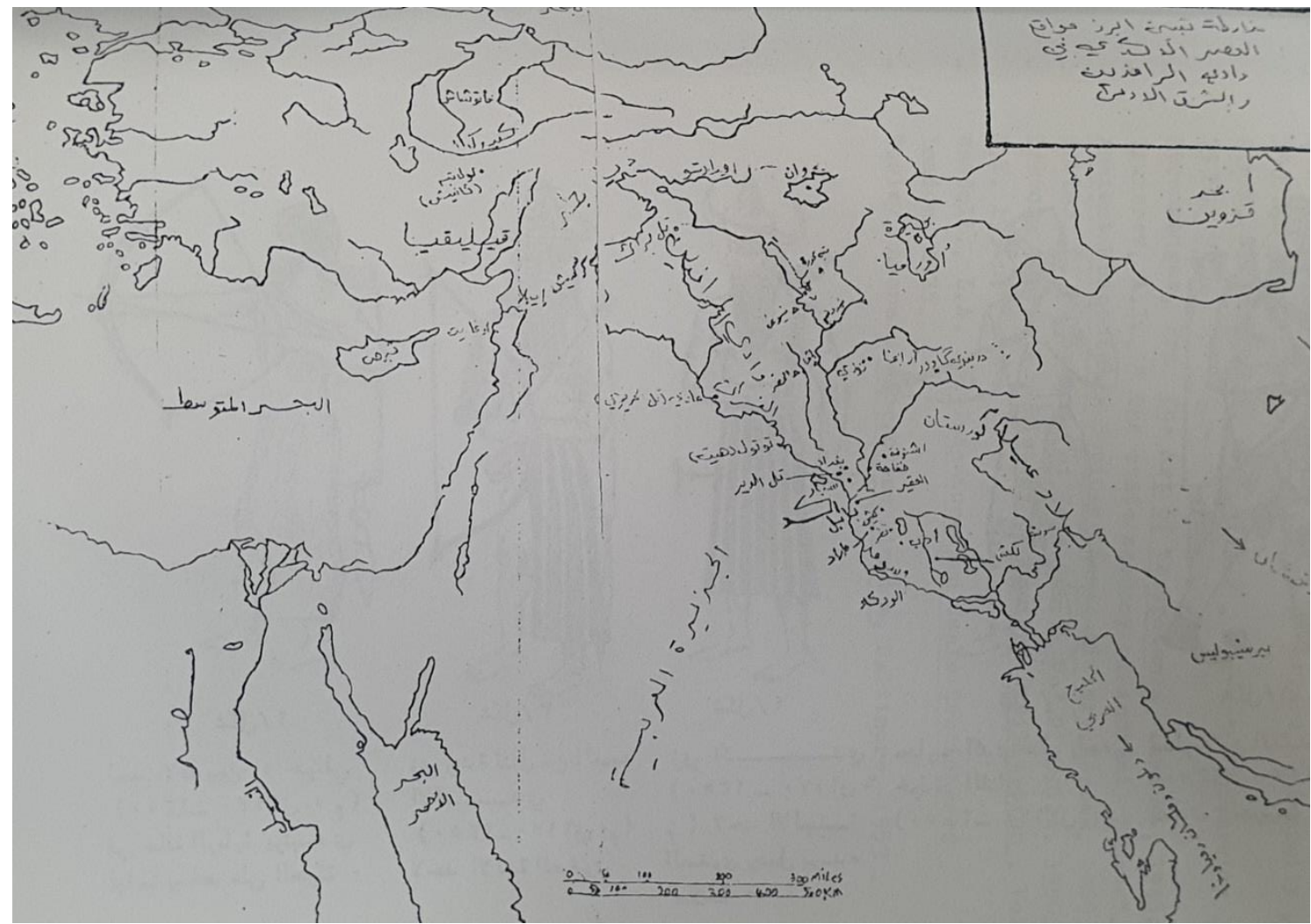

الثكل (1) رأس التمثال الذي يعتقد أنه يمثل سرجون الأكدي.
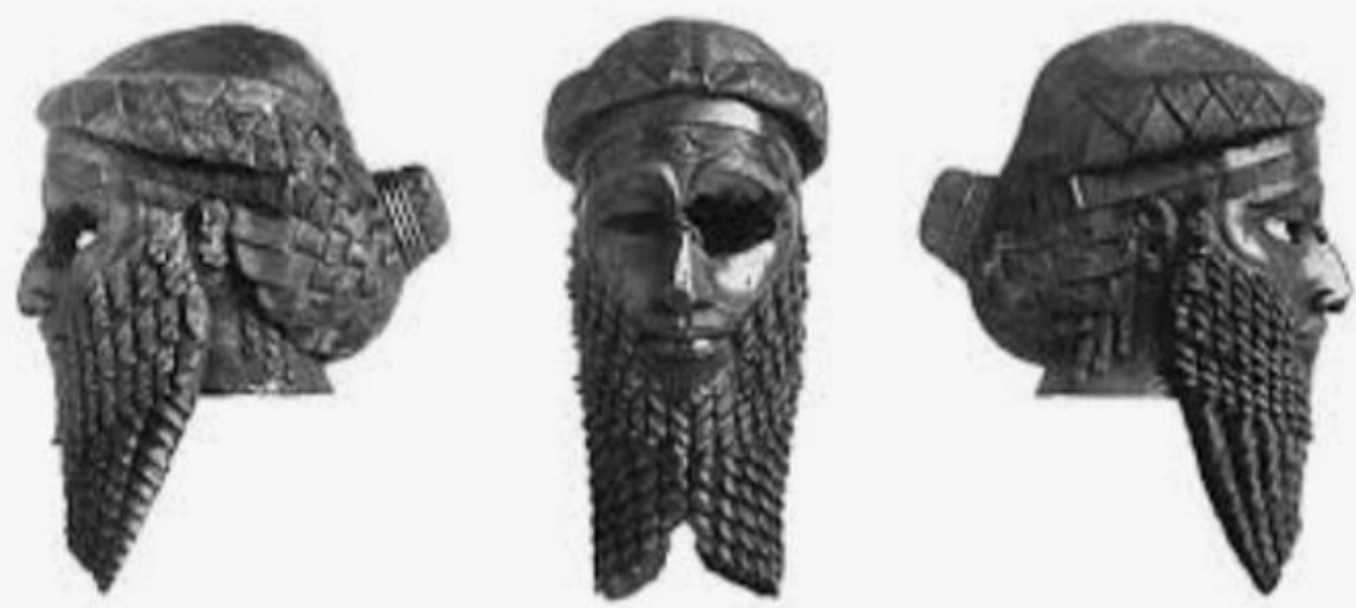


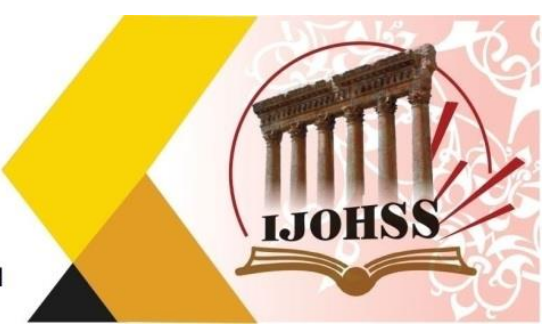

1. إبر اهيم أحمد زرقانة و محمد أنور شكري و عبد المنعم أبو بكر و حسن محمود و عبدالنعيم حسنين، حضارة

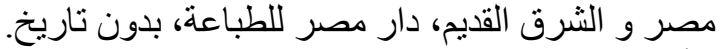

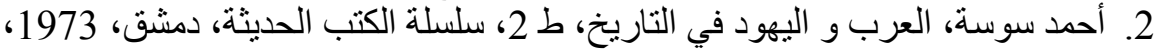

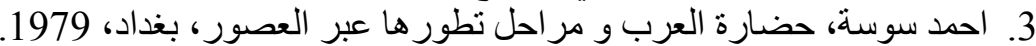

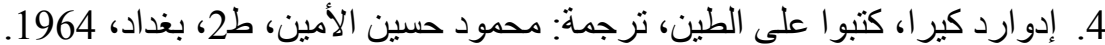

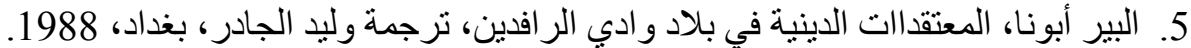

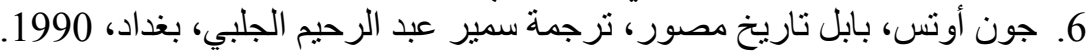

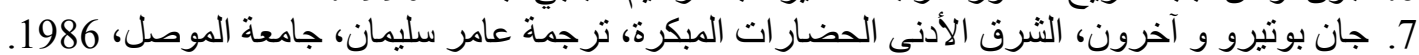
8.

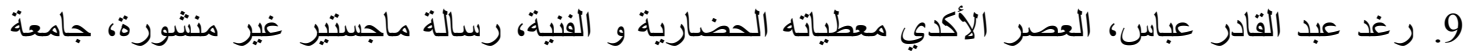

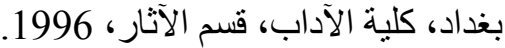

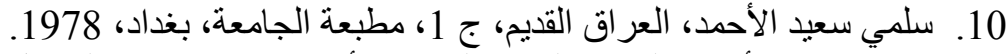

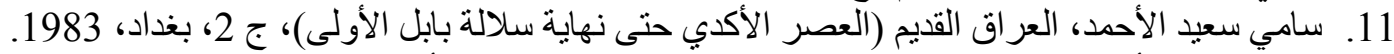

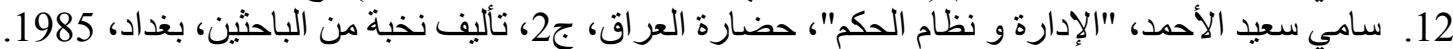

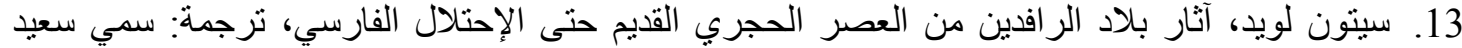

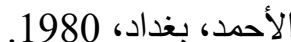

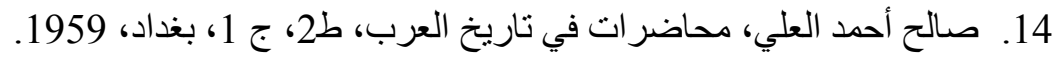

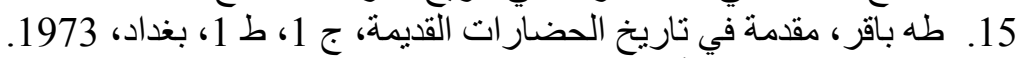

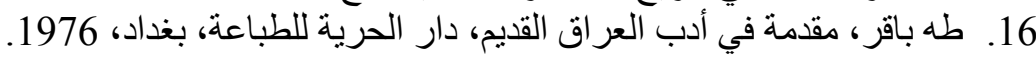

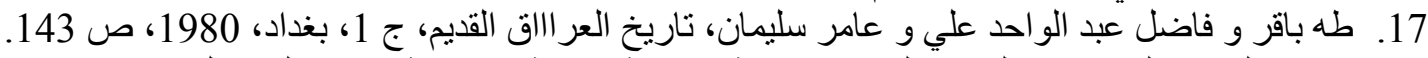

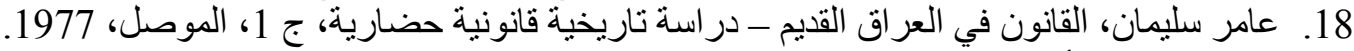

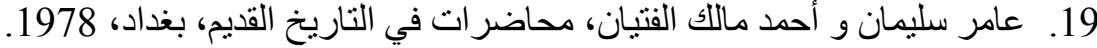

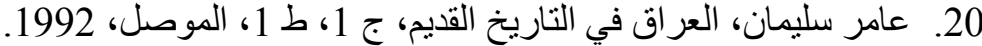

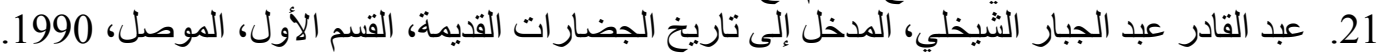

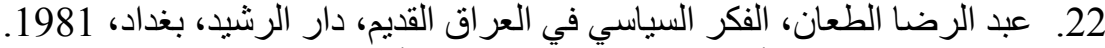

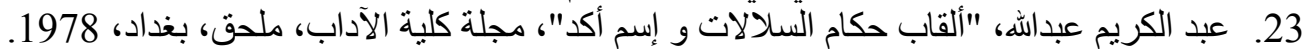

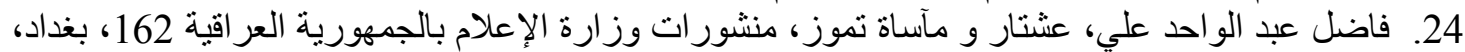

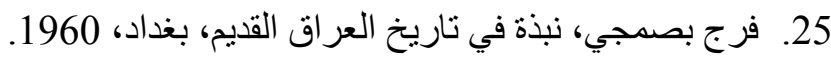

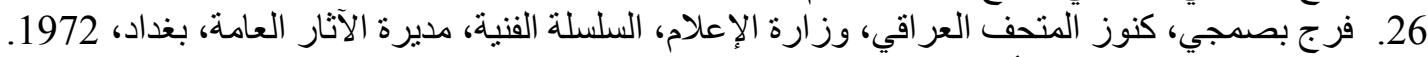

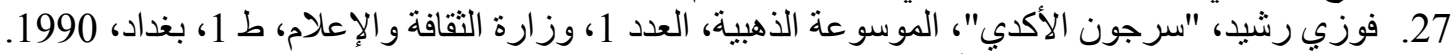

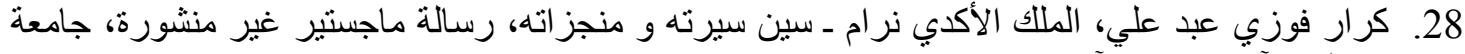

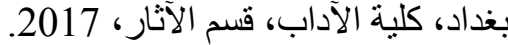

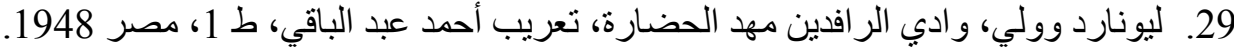

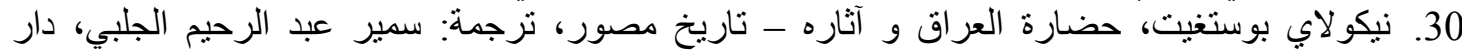
المأمون للترجمة و النشر، بغداد، 1991. 


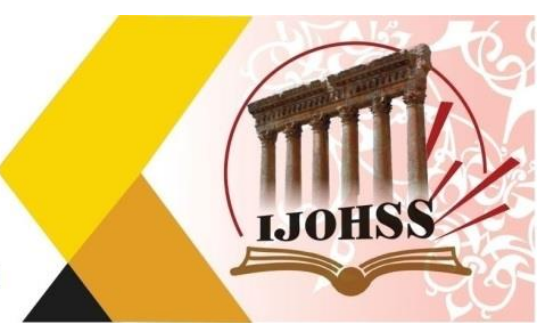

\section{References}

1. Adil Naji, Akkadian Cylinder Seals in the Iraq Museum, Unpublished M. A. Thesis, Birmingham University, 1965.

2. Brian Lewis, "The Sargon Legend", ASOR, Cambridge, 1980.

3. Brian Lewis, "The Sargon Legend- A Study of the Akkadian Text and the Tale of the Hero at Birth", JNES, Vol. 43, 1984.

4. C.J. Cadd, The Cambridge Ancient History, Vol. !, Part 2, Cambridge, 1971.

5. Drews Robert, "Sargon Cyrus and Mesopotamian Folk History", JNES, Vol. 33, No. 4, Chicago, 1947.

6. Dury, Carel J. ., Volker der Alten Orient, Baden, 1969.

7. Edmund I. Gordon, "Of Princes and Foxes: The Neck-Stock in the Newly Discovered Agade Period Stele", Sumer, Vol. XII, No. 1-2, Baghdad, 1956.

8. George Rawlinson, The Religions of the Ancient World, N.Y., 1885.

9. Henry Frankfort, Birth of Civilization in the Near East, New York, 1950.

10. Henry S. Lucas, A Short History of Civilization, York, 1943.

11. Erica Hunter, First civilization, Belgium, 1994, P. 53.

12. Jack Finegan, Light From the Ancient Past, U.S.A., 1954.

13. J. B. Pritchard, "Akkadian Myths and Epics", Edited by Speiser, ANET, New Jersey, 1969.

14. J.E.S. Edawrds, C. J. Cadd, N. E. L. Hammond, The Cambridge Ancient History, $3^{\text {rd }}$ Edition, Cambridge University Press, 1970.

15. Robert McC Adams, Land Behind Baghdad, Chicago, 1965.

16. S. C. F. Brandon, Religion in Ancient History, N. Y., 1969.

17. Schulze Franz., Art, Architecture and Civilization, University of Virginia, 1968.

18. Seton Lloyd E.S.A., Twin Rivers, Oxford, 1943, PP. 31-33.

19. Sidney Smith, Early History of Assyria to 1000 B.C., London, 1928, P. 82.

20. Mary, G. Hauslon., Ancient Egyptian Mesopotamian Persian Costume and Decoration, London, 1854.

21. Nicholas Postgate, The First empires, Belgium, 1977.

22. William W. Hallo and William K. Simpson., The Ancient Near East; A History, U.S.A., 1971. 